\title{
A comparison of antioxidant status and free radical peroxidation in healthy persons
}

Simmi Kharb*, Veena Singh Ghalaut*, P.S. Ghalaut ${ }^{\dagger}$

\begin{abstract}
Abstrak
Studi ini bertujuan memperoleh nilai acuan status antioksidan dan derajat peroksidasi pada orang dewasa sehat dan tidak merokok. Kadar malondialdehid (MDA), superoksida dismutase (SOD) dan vitamin E serum diukur dari 90 sukarelawan pria dan 110 wanita. Didapatkan MDA pada wanita $(2,07 \pm 0,79 \mathrm{nmol} / \mathrm{ml})$ lebih tinggi dari MDA pada pria $(1,87 \pm 1,20 \mathrm{nmol} / \mathrm{ml})$ sedangkan vitamin E pada serum wanita lebih rendah dibanding dengan pria $(16,99 \mathrm{vs} 20,02 \mu \mathrm{moLL})$. Terdapat korelasi terbalik antara kadar MDA dan vitamin E pada pria dan wanita.
\end{abstract}

\begin{abstract}
We measured lipoperoxide as malonaldehyde (MDA), superoxide dismutase (SOD) and vitamin E levels in serum from 90 nonsmoking men and 110 women volunteers. In the present study women had higher MDA values $(2.07 \pm 0.79 \mathrm{vs} 1.87 \pm 1.20 \mathrm{nmol} / \mathrm{ml})$ and lower vitamin $E$ levels $(16.99 \mathrm{vs} 20.02 \mu \mathrm{mol} / \mathrm{L})$ as compared to men $(p<0.05)$. An inverse relationship was observed between MDA and vitamin $E$ levels $(p<0.001)$.
\end{abstract}

Keywords: Lipid peroxidation, vitamin E, superoxide dismutase

The tissues in our body are continously exposed to reactive oxygen species (ROS) generated from endogenous and some exogenous sources. 'These are essential for many biological processes such as eicosanoid metabolism, host defense mechanism and as regulatory molecule eg. nitric oxide in the regulation of vascular function. ${ }^{1}$ These ROS may also contribute casually to a number of human degenerative diseases such as atherosclerosis, certain types of cancer and cataract. ${ }^{2}$ Oxidative damage to biomolecules is limited by a number of antioxidant defense systems, both enzymatic and non-enzymatic. Alpha tocopherol is a lipid soluble compound present in biological membranes and lipoproteins; it is by far the most abundant lipid soluble antioxidant in human. ${ }^{2}$ Alpha tocopheral is particularly effective as a chain breaking antioxidant, thus inhibiting lipid peroxidation and may play an important role in preventing atherogenic modification of low density lipoprotein (LDL). An important part of the intracellular antioxidant defense systems are antioxidant enzymes such as superoxide dismutase (SOD), catalase and peroxidase. SOD

\footnotetext{
${ }^{*}$ Department of Biochemistry and ${ }^{\dagger}$ Medicine Pt. B.D.Sharma, PGIMS, Rohtak, India
}

catalyses the reduction of superoxide anion which can be scavenged by catalase and peroxidase, and reversible interconversion of nitric oxide and nitroxyl anion. ${ }^{2}$ However, free radicals can become highly destructive if their productin is not tightly controlled resulting in peroxidative damage to lipid, protein and DNA. ${ }^{1}$ The clinical utility of measurement of parametes of oxidative stress requires reference values evaluated from a disease free population. In this report, the serum malonaldehyde (MDA), SOD and vitamin E levels are described for a healthy nonsmoking cohort of 200 adult ( 90 men and 110 women) volunteers after an overnight fasting.

\section{MATERIAL AND METHODS}

Subjects were nonsmokers, apparently healthy employees and medical students of Pt. B.D. Sharma PGIMS, Rohtak (India). Subjects were excluded from this screening if they had known endocrinologic disorders, diabetes mellitus, renal insufficiency, hepatic disease, illnesses characterized by an acute-phase response or history of taking lipid lowering drugs or vitamin E supplements. After overnight fasting peripheral venous blood was drawn. Serum was separated by centrifugation and biochemical studies were performed. Patients selected were in the age 
examined the acute effects of two different types of ginseng supplementation (Russian and Chinese) on strength development in males. Pectoral and quadriceps strength measures were significantly greater only in the group who had ingested the Chinese ginseng compared with controls.

Resistance exercise is becoming widely used and accepted, not only in sports training, but also in recreational and health related exercise as well as occupationally related training. Highly specialized and sophisticated resistance exercise programs are part of most athletic training programs today. The inclusion of resistance exercise equipment for recreational lifters in various types of physical and cardiac rehabilitation program is widespread. ${ }^{6}$ Although the physiological effects of resistance exercise on muscular strength and body composition have been extensively studied and widely report, ${ }^{7-10}$ no evidence is available in the literature regarding the effect of resistance exercise training with and without ginseng supplementation on strength development in young adults. Therefore the present study was designed to examine the effects of ginseng administration in combination with resistance exercise on strength development in males and females.

\section{MATERIALS AND METHODS}

\section{Subjects}

Thirty-three (21 male and 12 female, 21.0 \pm 1.5 years) normal healthy subjects volunteered to participate in this study. Subjects had not previously participated in an organized weight-training program, but were involved in other sports activities both before and during the duration of the study. Experiments were carried out on males and females in an attempt to compare the physical responses in both sexes. Ethical approval was obtained from the University Ethics Committee and an informed consent was procured from each subject before participation.

The subjects were divided into two experimental groups (i) resistance exercise with ginseng supplementation (GIN, N=14, 7 males, 7 females; (ii) resistance exercise without ginseng supplementation (PLA, $\mathrm{N}=19,14$ males, 5 females). The randomization between the two experimental groups was balanced by a rough estimation of body size, age and training status.

When subjects reported to the laboratory for testing, body mass and percentage body fat were determined. Percentage body fat was estimated from skinfold measurements as described by Durnin and Womersley. ${ }^{\text {II }}$

\section{Maximal resistance exercise testing before and after the training program}

After familiarization, the subjects were scheduled into morning pre-conditioning testing sessions. Subjects reported to the laboratory in pairs and were fed a standardized breakfast $(50 \mathrm{~g}$ cercal and $100 \mathrm{ml}$ of skimmed milk; energy $946 \mathrm{~kJ}$, carbohydrate $52 \mathrm{~g}$, protein $3.6 \mathrm{~g}$, and fat $0.4 \mathrm{~g}$ ). Maximal resistance exercise testing was conducted at the same time of day (08:00-12:00 hours) in an ambient temperature of $24 \pm 2^{\circ} \mathrm{C}$ and relative humidity of $55 \pm 5 \%$.

The maximal resistance exercise test consisted of the completion of three sets of seven different exercises using resistance (weight) corresponding to 15 repetition maximum (15 RM). The 15-RM strength was determined for each exercise to obtain measures of maximal resistance exercise volume for the upper and lower body parts. The 15 RM was defined as the maximal weight that could be lifted 15 times through the full range of motion employing the correct techniques. Resistance exercises performed were bench press, leg press, latissimus pull down, prone leg curl, shoulder press, leg extension and standing biceps curl. Rest periods interspaced exercises (30 s) and sets ( 120 $\mathrm{s})$. Exercise volume ( $\mathrm{kg}$ ) was calculated by multiplying the number of sets by the number of repetitions times the weight lifted per repetition. ${ }^{12}$

\section{Resistance exercise conditioning program}

All subjects in the two experimental groups exercised twice weekly for eight weeks. The sequence of exercises in the first profile was bench press, leg press, latissimus pull down, prone leg curl, shoulder press, leg extension, and standing biceps curl. In the second profile the sequence of exercises was shoulder press, leg press, latissimus pull down, leg extension, bench press, prone leg curl and standing biceps curl. Both these sequences of exercise were arranged so that the multi-joint exercises using the largest muscle mass and requiring the greatest effort came first in the order. Maximal strengths of major muscle groups for upper and lower body parts were determined in both experimental groups before and after the training period using 15 RM. Subjects were continually encouraged to push themselves and increase both repetitions and the weight lifted. When subjects improved in strength, weights were progressively increased to elicit 15 RM for each exercise. 


\section{Ginseng and placebo tablets administration proce- dures}

Subjects were randomly assigned to receive either the ginseng supplement or placebo. Ginseng $(600 \mathrm{mg}$ Panax ginseng, Red Korean ginseng) or placebo (sugar-free) tablets were ingested daily on weekdays between 16.30 and 19:00 hours. Tablets were kept in coded bottles and administered in a double blind fashion.

\section{Statistical analysis}

The statistical analysis of the data were carried out using analysis of variance (ANOVA) with repeated measurements. The dependent variables body mass, percentage body fat, and strength indices was entered into two $2 \times 2$ ANOVA models to detect differences between ginseng-placebo and pre-post conditioning tests and between male-female and pre-post conditioning tests, respectively. A level of $\mathrm{p}<0.05$ was chosen to indicate significance.

\section{RESULTS}

Body mass and estimated percentage body fat before and after the conditioning program.

Table 1. Body mass and estimated percentage body fat in males $(\mathrm{N}=21)$ and females $(\mathrm{N}=12)$ before $(\mathrm{A})$ and after (B) conditioning.

\begin{tabular}{clll}
\hline & & $\mathrm{A}$ & $\mathrm{B}$ \\
\hline $\begin{array}{c}\text { Weight } \\
(\mathrm{kg})\end{array}$ & Males & $72.0 \pm 1.5^{*}$ & $72.3 \pm 1.7^{*}$ \\
Body fat & Males & $15.4 \pm 1.1^{+}$ & $16.2 \pm 1.0^{+}$ \\
$(\%)$ & Females & $27.2 \pm 1.6$ & $29.6 \pm 1.7$ \\
\hline
\end{tabular}

* significantly $(\mathrm{P}<0.05)$ higher than that observed in females.

${ }^{+}$significantly $(\mathrm{P}<0.05)$ lower than that observed in females.

Table I shows the mean values of body mass and estimated percentage body fat in males and females before and after the conditioning program. Body mass was significantly $(p<0.05)$ higher in males compared with that observed in females both before and after the conditioning program. Resistance exercise training induced no significant change in body mass in males or females.

Percentage body fat was significantly $(p<0.05)$ higher in females compared with that found in males. This was found both before and after conditioning. The statistical comparison of the mean values of the percentage body fat before and after conditioning also revealed no significant differences in either males and females.

Table 2. Body mass and estimated percentage body fat for placebo $(\mathrm{N}=19)$ and ginseng $(\mathrm{N}=14)$ before $(A)$ and after $(\mathrm{B})$ conditioning.

\begin{tabular}{clcc}
\hline & & A & B \\
\hline $\begin{array}{c}\text { Weight } \\
(\mathrm{kg})\end{array}$ & Placebo & $69.4 \pm 2.3$ & $68.5 \pm 2.3$ \\
Gody fat & Placebo & $21.2 \pm 2.2$ & $22.2 \pm 2.1$ \\
$(\%)$ & Ginseng & $17.9 \pm 2.0$ & $20.2 \pm 2.3$ \\
\hline
\end{tabular}

The results of body mass and estimated percentage body fat for placebo and ginseng groups before and after the conditioning program are presented in Table 2. The mean values of body mass did not vary significantly between placebo and ginseng groups either before or after conditioning. Likewise, no statistically significant change in body mass was observed in response to the conditioning program in any group.

No statistically significant difference in the percentage body fat was observed between placebo and ginseng groups before the conditioning program. Resistance exercise training induced no statistically significant change in percentage body fat in any of the groups studied.

\section{Strength development in response to the resis- tance exercise conditioning program.}

Muscular strength, expressed as total exercise volume, in male and female groups before and after the conditioning program is presented in Figure 1. Males generated significantly $(p<0.001)$ greater exercise volume in compared with females before and after the conditioning program. The average percentage gain in term of total exercise volume was $18.1 \%$ for males and $17.9 \%$ for females, this differences was not statistically significant $(\mathrm{p}=0.70)$.

Total exercise volumes in placebo and ginseng groups before and after the conditioning program are graphically depicted in Figure 2. Muscular strength expressed as total exercise volume, increased significantly $(\mathrm{p}<0.05)$ after the conditioning program with no statistically significant differences being observed between groups. The average percentage gain in terms of total exercise volume was $14 \%$ for the 
placebo group and $20 \%$ for the ginseng group, these differences were not statistically significant $(\mathrm{p}=0.90)$.

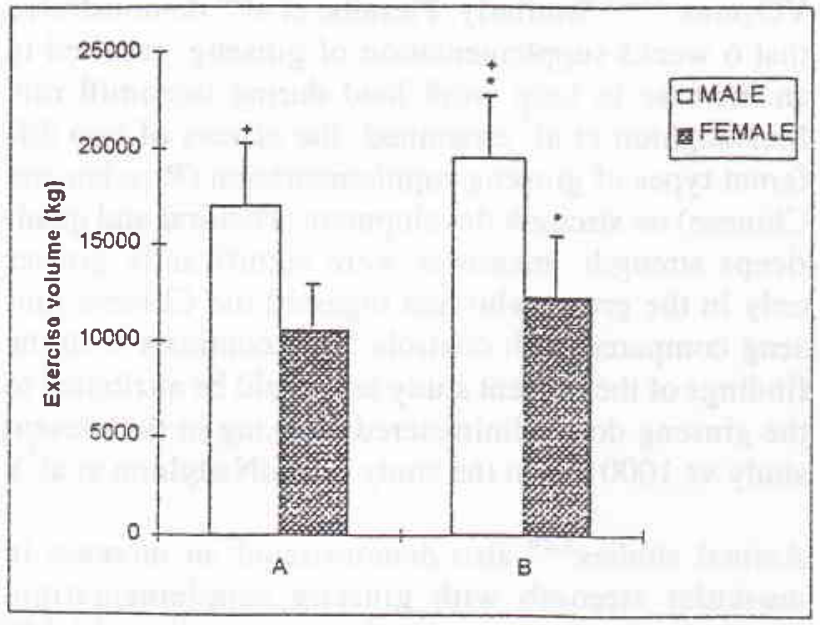

Figure 1. Exercise volume (mean $\pm S D)$ in male $(N=21)$ and female $(N=12)$ groups before $(A)$ and after $(B)$ conditioning. ${ }^{+}$significantly higher $(p<0.001)$ mean value than that observed in females. *significantly higher $(p<0.05)$ than that observed before conditioning.

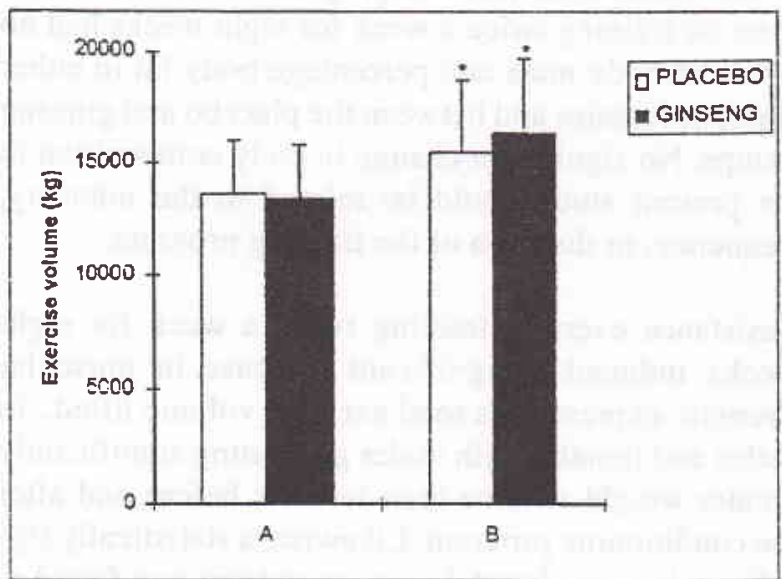

Figure 2. Exercise volume (mean $\pm S D)$ in placebo $(N=19)$ and ginseng ( $N=14$ ) groups before (A) and after (B) conditioning. *significantly higher $(p<0.05)$ mean value than that observed before conditioning.

\section{DISCUSSION}

The effect of resistance exercise conditioning program on body mass and estimated percentage body fat

Body mass was significantly greater in males compared with females both before and after the conditioning program. Percentage body fat was significantly higher in females compared with males both before and after conditioning. These data are normal for such a population.

The resistance exercise conditioning program had no effect on body mass and percentage body fat in either males or females. This is in agreement with Wilmore et al ${ }^{13}$ who found no significant changes in body mass and percentage body fat in either sex after a 10 -week circuit weight-training program encompassing 3 circuits of 10 stations, 3 days per week. Data also concur with the findings of Kokkinos et al ${ }^{14}$ who compared low and high-repetition resistance exercise training programs and found no significant changes in body mass and percentage body fat after 10 weeks of training. It should be noted, however, that Wilmore et al ${ }^{13}$ and Kokkinos et al ${ }^{14}$ found an increase in lean body mass in response to resistance exercise training. Other investigators ${ }^{15}$ found a decrease in percentage body fat in males and females after 16 weeks of weight-training. The fact that the decrease in the percentage body fat was not statistically significant in the present study may probably be linked with the duration of the training program which was only 8 weeks. Pollock ${ }^{16}$ stated that programs of 8 to 10 weeks duration generally result in less changes in body composition parameters compared with longer duration. However, this is not always the case. For example, Hurley et a ${ }^{17}$ failed to demonstrate a significant changes in body composition after 16-week high-intensity resistive training on 11 healthy untrained males.

The present work also showed that body mass and percentage body fat did not change significantly between placebo and ginseng groups in response to resistance exercise training. No data secm to be available in the literature regarding the effect of ginseng supplementation on body composition in humans. Animal studies showed that ginseng supplementation increased the body weight of mice, ${ }^{18}$ but it was not clear whether this increase was due to an increase in lean body mass, fatty tissue or water retention. High doses of ginseng which have been used in these animal studies would not be considered safe in humans. Thus it is suggested that ginseng ingested in a dose com- 
patible with safety $\left(600 \mathrm{mg} \cdot \mathrm{day}^{-1}\right)$ had no effect on body composition.

\section{The effect of resistance exercise conditioning pro- gram on strength development}

Muscular strength, as measured in total exercise volume lifted, was significantly greater in males compared with females before and after the conditioning program. These data are in agreement with the results of previous research ${ }^{19}$ which showed that total body strength in females was $63.5 \%$ compared with males. Females' upper and lower body strength were $55.8 \%$ and $71.9 \%$, respectively, compared with muscular strength in males. It appears that when the effects of additional habitual physical activities are taken into account, the strength gain in response to resistance exercise training in males and females are directly related to lean body mass. Falkel et $\mathrm{al}^{8}$ found that the arm and leg strengths of males and females as measured on an isokinetic dynamometer were equal when expressed relative to lean body mass. One of the factors responsible for the difference in lean body mass between males and females is likely be due to a greater level of androgens in males. ${ }^{20}$

Males and females exhibited $18.1 \%$ and $17.9 \%$ in strength gain following resistance exercise training. These data are in agreement with the findings of Wilmore et al ${ }^{13}$ who reported similar strength gains after weight training in men and women. The absence of significant changes in body composition and the increase in strength performance in the present study could be due to neural mechanisms. This is based on the evidence that strength development in studies of 8-20 weeks duration is mainly associated with neural adaptations such as improved co-ordination and learning and increased activation of the muscles acting as prime movers. ${ }^{21}$ Wilmore and Costill ${ }^{22}$ revealed that motor unit recruitment is a key factor in strength gains. It has been generally accepted that whether the muscle fibers contract or relax depends on the summation of the many impulses received by that motor unit at any one time. Strength gains may result from recruitment of additional motor units to act synchronously, facilitating contraction and increasing the muscle's ability to generate force. ${ }^{22}$

Resistance exercise training induced similar increases in muscular strength in placebo and ginseng groups (14\% in the placebo group and $20 \%$ in the ginseng group). This finding suggests that there was no additional ergogenic effect of ginseng $\left(600 \mathrm{mg}\right.$.day $\left.{ }^{1}\right)$ on the development of muscular strength in response to resis- tance exercise training. Most of the previous studies employed endurance exercise to assess the ergogenic effects of ginseng supplementation on physical performance. These studied showed that ginseng ingestion improves maximal aerobic power as assessed by $\mathrm{VO}_{2} \max .^{23,24}$ Similarly, Pieralisi et al ${ }^{25}$ demonstrated that 6 weeks supplementation of ginseng resulted in an increase in total work load during treadmill run. McNaughton et al ${ }^{5}$ examined the effects of two different types of ginseng supplementation (Russian and Chinese) on strength development. Pectoral and quadriceps strength measures were significantly greater only in the group who had ingested the Chinese ginseng compared with controls. This contrasts with the findings of the present study and could be attributed to the ginseng dose administered $(600 \mathrm{mg}$ in the present study vs $1000 \mathrm{mg}$ in the study of McNaughton et $\mathrm{al}^{5}$ ).

Animal studies ${ }^{3,26}$ also demonstrated an increase in muscular strength with ginseng supplementation. However, the doses used in the latter studies (15-150 $\mathrm{mg} \cdot \mathrm{kg}^{-1}$ body weight.day ${ }^{-1}$ ) were substantially higher than the dose administered in the present investigation. It is possible that the administration of a higher dose of ginseng enhances muscular strength. Because it has long been recognized that higher doses of ginseng ingestion lead to side effects ${ }^{27}$, in the present study a dose $(600 \mathrm{mg})$ compatible with safety was administered.

\section{CONCLUSION}

It was established that the program of the resistance exercise training twice a week for eight weeks had no effect on body mass and percentage body fat in either males or females and between the placebo and ginseng groups. No significant change in body composition in the present study could be related to the intensity, frequency, or duration of the training program.

Resistance exercise training twice a week for eight weeks induced a significant increase in muscular strength, expressed as total exercise volume lifted, in males and females with males generating significantly greater weight volume than females before and after the conditioning program. Likewise, a statistically significant increase in total exercise volume was found as a result of the resistance exercise training, with no difference being observed between the placebo and the ginseng group post-training. The absence of significant changes in body composition and the increase in strength performance in the present study could be due to neural mechanisms. 


\section{Acknowledgments}

Many thanks to Dr. Mahmoud El-Sayed, FACSM and Prof. Dr. Thomas Reilly, Center for Sport and Exercise Sciences, School of Human Sciences, Liverpool John Moores University, England for their supports and advises throughout the course of the work. My appreciation is also extended to all the participants of this study without whom the research would not have been possible.

\section{REFERENCES}

1. Goldstein B. Ginseng: its history, dispersion, and folk tradition. Am J Chinese Med 1975; 3: 223-34.

2. Cartwright L. Ginseng in pharmacies. Australian J Pharm 1979;3:346-9.

3. Popov IM, Goldwald WJ. A review of the properties and clinical effects of ginseng. Am J Chinese Med 1973;1:26370.

4. Kirchdorfer AM. Clinical trials with the standardized ginsenoside concentrate G115. In Chang HM, Yeung HW, Tso W. Koo A, editors. Advances in Chinese Medicinal Materials Research. Singapore, World Scientific Publication Company; 1985. p. 29-42.

5. McNaughton L, Egan D, Caelli G. A comparison of Chinese and Russian ginseng as ergogenic aids to improve various facets of physical fitness. Int Clin Nutr Review 1989;9:32-6.

6. Fleck SJ, Kraemer WJ. Designing Resistance Training Programs. Champaign, IL.: Human Kinetics; 1988.

7. Getmann LR, Ayres JJ, Pollock ML. The effect of circuit weight training on strength, cardiorespiratory function, and body composition of adult men. Med Sci Sports Exerc 1978;10:171-6.

8. Falkel JE, Sawka MN, Levine L, Pandolf KB. Upper to lower body muscular strength and endurance ratios for female and male. Ergonomics 1985;28: 1661-70.

9. Dudley GA. Metabolic consequences of resistive-type exercise. Med Sci Sports Exerc 1988;20 Suppl 1:158-61.

10. Enoka RM. Muscle strength and its development: New perspectives. Sports Med 1988; 6: 146-68.

11. Durnin JG, Womersley J. Body fat assessed from total body density and its estimation from skinfold thickness; measurements on 481 men and women aged 16 to 72 years. Br J Nutr 1974; 21: 77-97
12. Wathen D. Training volume. In : Baechle TR, editor. Essentials of strength training and conditioning. Campaign IL, Human Kinetics; 1994.p. 447-50.

13. Wilmore JH, Parr RB, Girandola RN, Ward P, Vodak, PA, Barstow TJ, et al. Physiological alterations consequent to circuit weight training. Med Sci Sports 1978;10:79-84.

14. Kokkinos PF, Hurley BF, Vaccaro P, Patterson JC, Gardner LB, Ostrove SM et al. Effects of low- and high-repetition resistive training on lipoprotein-lipid profiles. Med Sci Sports Exerc 1988; 20:50-4

15. Goldberg L, Elliot DL, Schultz RW, Kloster FE. Changes in lipid and lipoprotein level after weight training. JAMA 1984;252:504-6

16. Pollock ML. The quantification ef endurance training programs. In Wilmore JH, editor. Exercise and Sport Sciences Review. New York Academic Press; 1973. p.155-8.

17. Hurley BF, Hagberg M, Goldberg AP, Seals DR, Ehsani AA, Brennan RE et al. Resistive training can reduced coronary risk factors without altering $\mathrm{VO}_{2} \max$ or percent body fat Med Sci Sports Exerc 1988; 20:150-4.

18. Kim HS. The effect of ginseng administration on body mass in rats. Am J Chinese Med 1970; 7:23-9.

19. Laubach LL. Comparative muscular strength of men and women : A review of the literature. Aviation, Space and Envir Med 1976;47:534-42.

20. Kraemer WJ, Noble BJ, Clark MJ and Culver BW. Physiologic responses to heavy-resistance exercise with very short resting periods. Int J Sports Med 1987;8:247-52.

21. Sale DG. Neuroadaptation to resistance training. Med Sci Sports Exerc 1988;20: Suppl 1:135-45.

22. Wilmore JH, Costill DL. Physiology of sport and exercise. Champaign IL.: Human Kinetics; 1994

23. Forgo I, Kirchdorfer AM. The effect of different ginsenoside concentrations on physical work capacity. Notabene Med 1982;12:721-7.

24. Forgo I, Schimert G. The duration of effect of the standardized ginseng extract G115 in healthy competitive athletes. Notabene Med 1985;15:636-40.

25. Pierallisi G, Ripari P, Vecchiet L. Effects of standardized ginseng extract combined with dimethylaminoethanol bitartrate, vitamins, minerals, and trace elements on physical performance during exercise. Clinical Therapy 1991;13:373-82.

26. Filaretov AA, Bogdanova TS, Podvigina TT, Bodganova AI Role of pituitary-adrenocortical system in body adaptation abilities. Exp Clin Endocrinology 1988;92:129-36.

27. Siegel RK. Ginseng and high blood pressure. JAMA 1979;243:32. 
group 22-40 years. The lipid profile was estimated enzymatically. Serum MDA was estimated by thiobarbituric acid reaction. ${ }^{3}$ Serum vitamin $\mathrm{E}$ was assayed spectrofluorometrically. ${ }_{5}^{4}$ SOD levels were estimated spectrophotometrically. ${ }^{5}$ To better identify the plasma status of vitamin $\mathrm{E}$, the ratio of vitamin $\mathrm{E}$ to lipids (in $\mu \mathrm{mol} / \mathrm{g}$ ) was determined as the ratio of vitamin $\mathrm{E}$ to total cholesterol plus triglycerides. ${ }^{6}$ Data was analysed by using student's t-test and regression analysis.

\section{RESULTS}

The study comprised 200 apparently healthy, nonsmoking adults, 90 men and 110 women. Women had higher values of MDA (mean \pm SD: $2.07 \pm 0.79$ $\mathrm{nmol} / \mathrm{ml})$ as compared to mean $(1.87 \pm 1.20 \mathrm{nmol} / \mathrm{ml})$, $(\mathrm{p}<0.05)$. Mean serum vitamin $\mathrm{E}$ levels were lower in women (16.99 $\pm 8.06 \mu \mathrm{mol} / 1$, range 7.82-41.19) as compared to men $(20.02 \pm 6.85 \mu \mathrm{mol} / \mathrm{L}$, range 6.80 41.18). Thus, and inverse relationship was observed between MDA and vitamin E levels $r=0.99, \mathrm{p}<0.001$ ). Serum total cholesterol was $160 \pm 26.31 \mathrm{mg} \%$ and triglycerides were $127 \pm 22.5 \mathrm{mg} \%$. Also, vitamin $\mathrm{E}$ to total lipid ratio was higher in men than in women $(7.66$ vs $6.92 \mu \mathrm{mol} / \mathrm{g}$ ). Mean SOD levels were $173 \pm 14.70$ EU and no statistically significant difference could be observed between men and women.

\section{DISCUSSION}

Lipid peroxidation is a process normally occurring at low levels in all cells and tissues. ${ }^{6}$ Low levels of lipid peroxidation are essential to many normal cellular processes in that small amounts of lipid peroxides and semistable breakdown products act as intracellular and extracellular messengers. ${ }^{6}$ Although a variety of antioxidant mechanisms serve to control lipid peroxidation, under certain conditions, the protective mechanisms can be overwhelmed leading to elevated steady state tissue levels of peroxidation products., To our knowledge no report is available regarding reference values for lipid peroxidation and antioxidant status from a healthy nonsmoking population. However, reports are available regarding nutritional survey of vitamin $E$ in healthy population. ${ }^{8}$ In the present study women had higher MDA levels as compared to men. The cause for higher MDA levels in women is not clear. This could be due to lower antioxidant vitamin $\mathrm{E}$ status in women. Although demonstrable vitamin $\mathrm{E}$ inadequacy in apparently healthy adults is rare, vitamin $\mathrm{E}$ requirements may vary in individuals depending on the dietary intake of polyunsaturated fatty acids, tissue composition, the steady state concentration of other interactive antioxidants in tissues and genetic factors. ${ }^{7}$ The vitamin $\mathrm{E}$ concentration in serum correlates with the levels of circulating lipids in the present study, and concurrent knowledge of the lipid level, makes the serum vitamin E concentration a much reliable index of the vitamin $E$ status of the individual. ${ }^{9}$ Free radical mediated damage has been implicated in cellular and extracellular changes that occur over time in the aging process and in the development of chronic disease. ${ }^{2, T}$ Vitamin $\mathrm{E}$ and other antioxidants such as SOD prevent or minimize oxidative damage in biological systems. This is a preliminary report regarding lipid peroxidation and antioxidants status in healthy population. Vitamin E determination may improve identification and risk stratification of patients at risk of chronic degenerative diseases, coronary artery disease and cancer.

\section{REFERENCES}

1. Frei B. Reactive oxygen species and antioxidant vitamins : mechanism of action. Am J Med 1994; 97 (Suppl 3A): 5S-13S.

2. Sie SH. Strategies of antioxidant defense. Eur $\mathbf{J}$ Biochem 1993; 215:213-9.

3. Placer ZA, Cushmann LL, Johson BC. Estimation of products of lipid peroxidation in biological systems. Anal Biochem 1960; 16:359-64.

4. Duggan DE. Spectrofluorometric determination of tocopherols. Arch Biochem Biophys 1950; 84:166-20.

5. Misra HL, Fridovich I. The role of superoxide anions in the autooxidation of epinephrine and a simple assay for superoxide dismutase. J Biol Chem 1972; 247:3170-5.

6. Kehrer JP, Smith CV. Free radicals in biology : sources, reactivities and role in the etiology of human diseases. In Frei $B$, ed. Natural antioxidants in human health and disease. Orlando, FL: Academic Press, 1994; 25-62.

7. Packer L. Interactions among antioxidants in health and disease: Vitamin E and its redox cycle. Proc Soc Expl Biol Med 1992; 200: 271-6.

8. Bieri J, Teets GL, Belavady B, Andrews EL. Serum vitamin E levels in a normal adult population in the Washington D.C. area. Proc Soc Exptl Biol Med 1964; 177:131-3.

9. Rubinstein HM, Dietz AA, Srinivasan R. Relationship of vitamin E and serum lipids. Clin Chim Acta 1969; 23:1-5. 